\title{
OXIDATION OF CROTONIC ACID WITH CE (IV) PERCHLORATES
}

\author{
1Department of Chemistry, D.B.S. (P.G.) College, Kanpur, India. \\ 2Department of Chemistry, D.G. (P.G.)College, Kanpur, India. \\ *Corresponding Author: Email- drictiwari@yahoo.co.in
}

RAJESH SHUKLA1', SUSHMA RANI2 AND TEWARI I.C. ${ }^{1 *}$

Received: May 05, 2012; Accepted: May 10, 2012

\begin{abstract}
The present manuscript deals the kinetics and mechanism of the reaction between crotonic acid and ceric perchlorates. The order of the reaction with respect to $\mathrm{Ce}$ (IV) is unity but the rate is dependent on the initial concentration of the Ce (IV). The spectrophotometric investigation has been also carried out which negatived the intermediate complex formation. The main reaction species of Ce (IV) involved in rate determining step was the hydrated uncomplexed ceric ion which at higher initial concentration gets dimerises.
\end{abstract}

Key words-

Citation: Rajesh Shukla, Sushma Rani and Tewari I.C. (2012) Oxidation of Crotonic Acid With Ce (Iv) Perchlorates. International Journal of Chemical Research, ISSN: 0975-3699 \& E-ISSN: 0975-9131, Volume 4, Issue 1, pp.-122-125.

Copyright: Copyright@2012 Rajesh Shukla, et al. This is an open-access article distributed under the terms of the Creative Commons Attribution License, which permits unrestricted use, distribution, and reproduction in any medium, provided the original author and source are credited.

\section{Introduction}

Although the kinetics investigation of various organic compounds with the $\mathrm{Ce}(\mathrm{IV})$ ion has been attempted by many authors [1-7] but the oxidation of unsaturated carboxylic acids has yet not been reported. The X-rays diffraction studies have clearly indicated the existence of the cerium (IV) salts as Ce (IV) acetylacetonate [8], $\mathrm{Ce}$ (IV) tetrakis(dibenzoylmethane) [9] and $\mathrm{Ce}$ (IV) disalicylalpropalenediammine [10] where the coordination number of $\mathrm{Ce}$ (IV) is eight. It seems most likely that the sulphate [11] and nitrate salts which are also eight coordinated having one coordination site may be occupied either by the oxygen atom of a single nitrate or the sulphate ion. In solution, the solvent may occupy the coordination sites so that eight coordinate of $\mathrm{Ce}$ (IV) is maintained. In past twenty to thirty years a little bit of work had been performed on the kinetics of the oxidation of organic acid by cerium [12-16]. But there is lots of work was remains untouched so far. The present manuscript deals the studies based on kinetics and mechanism of the reaction between crotonic acid and ceric perchlorates.

\begin{abstract}
Experimental
The progress of the reaction was studied by taking the required volume of ceric perchlorate solution along with adjustable quantity of perchloric acid and distilled water in a reaction vessel painted black toward off any photochemical change. The reaction vessel and the crotonic acid in another vessel were kept at constant temperature in a thermostat. The reactants were mixed by pouring in the required amount of crotonic acid. Aliquots $(5.00 \mathrm{ml}$ of reaction mixture) were withdrawn at different time intervals and poured into the flask containing the slight excess of standard ferrous ammonium sulphate solution. The excess of ferrous ammonium sulphate was titrated against a standard solution of ceric sulphate using ferroin as an indictor. The concentration of ceric perchlorate at various time intervals was determined by the method described by Szaleo [17].
\end{abstract}

\section{Materials}

Ceric perchlorate was prepared [18] from the analytical L.R. quality of B.D.H. ceric ammonium nitrate. Crotonic acid employed was 
A.R. grade (KOCH-LIGHT LABORATORY LTD.).The other reagents used were, perchloric acid (Riedel, $60 \%$ ), sodium perchlorate (Riedel grade), barium perchlorate (E. Merk, Germany), sodium hydroxide A.R. (B.D.H.), ferrous ammonium sulphate A.R. (B.D.H.) and ferroin (E. Merk).

\section{Results and Discussion}

\section{Stoichiometric and Product Analysis}

A known excess of $\mathrm{Ce}$ (IV)-perchlorate and a fixed amount of crotonic acid were allowed to react completely and after three months the unchanged $\mathrm{Ce}(\mathrm{IV})$ was estimated volumetrically. The stoichiometric ratios are given in Table-1.

Table-1 Stoichiometric and Product Analysis

\begin{tabular}{|lll|}
{$[$ Crotonic acid] X } & $\begin{array}{l}\text { [Ceric perchlorate] } \\
\text { X }\end{array}$ & {$[\mathrm{Ce}(\mathrm{IV})]$ ] [Crotonic acid] } \\
$10^{3 \mathrm{M}}$ & 1.67 & 11.234 \\
1.00 & 2.00 & 10.987 \\
1.00 & 2.50 & 11.474 \\
1.00 & \\
\hline
\end{tabular}

Temperature $=30^{\circ} \mathrm{C}$

The identification of product was carried out by ascending type of paper-chromatography using n-butanol saturated with ammonia as solvent system and bromophenol blue as spot revealing agents. Spots having $R_{f}$ values 0.61 and 0.49 characterizes the presence of acetic acid and formic acid.

The kinetic measurement have shown that in a given run the rate of disappearance of $\mathrm{Ce}(\mathrm{IV})$ follows a first order rate expression and the value of first order rate constant $k_{1}$ decreases with the increase in the initial concentration of $\mathrm{Ce}(\mathrm{IV})$.

Table-2 Effect of changing Ce (IV) concentration on the rate of perchlorate oxidation of crotonic acid

\begin{tabular}{|llllllll|}
\hline $\begin{array}{l}\text { [Ceric perchlo- } \\
\text { rate] } \mathrm{X} 10^{3} \mathrm{M}\end{array}$ & 6.67 & 5.00 & 4.00 & 2.86 & 2.00 & 1.54 & 1.25 \\
$\mathrm{k}_{1} \mathrm{X} 10^{4} \mathrm{sec}^{-1}$ & 0.499 & 0.633 & 0.685 & 0.799 & 1.141 & 1.279 & 1.559 \\
\hline
\end{tabular}

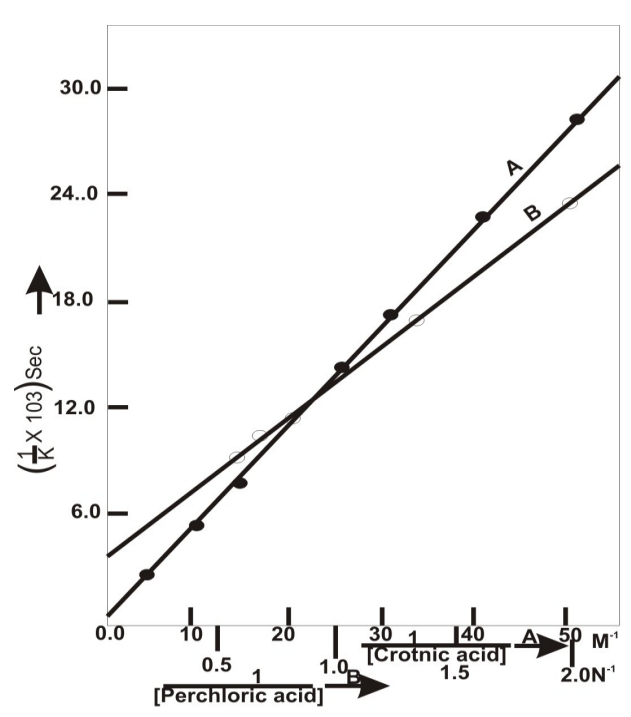

Fig. 1- Plot $A(\bullet)$ shows the variation of inverse rate with crotomic acid concentration in $1 \mathrm{n}-\mathrm{HciO}_{4}$ and $\left[\mathrm{ce}(\mathrm{clo} 4)_{-4]}=4.00 \times 10^{-3} \mathrm{~N}\right.$.
Temperature $=50^{\circ} \mathrm{C} ;[$ Crotonic acid $]=4.00 \times 10^{2} \mathrm{M}$ and $[$ Perchloric acid $]=1.00 \mathrm{~N}$

In Plot (O), the inverse rate is plotted against the inverse perchloric acid concentration; [Crotomic acid] $=4.00 \times 10^{-2} \mathrm{M}$,[ce(clo4)-4]

The order of the reaction with respect to crotonic acid has been found to be unity (Table-3). The plot of $1 /$ [crotonic acid] against $1 /$ $\mathrm{k}_{1}$ is a straight line passing through the origin (Figure-1).

Table-3 Rate dependence on the changing concentration of crotonic acid

\begin{tabular}{|llllllll|}
\hline Crotonic acid] & 20.00 & 10.00 & 6.67 & 4.00 & 3.33 & 2.50 & 2.00 \\
X $10^{2} \mathrm{M}$ & & & & & & & \\
$\mathrm{k}_{1} \times 10^{4} \mathrm{sec}^{-1}$ & 3.951 & 1.919 & 1.296 & 0.685 & 0.558 & 0.431 & 0.354 \\
$\mathrm{k}_{1} \times 10^{3} /$ & 1.976 & 1.919 & 1.943 & 1.712 & 1.676 & 1.724 & 1.770 \\
[crotonic acid] & & & & & & & \\
\hline
\end{tabular}

Temperature $=50^{\circ} \mathrm{C} ;$ [Ceric perchlorate $]=4.00 \times 10^{-3} \mathrm{~N}$ and [Perchloric acid] $=1.00 \mathrm{~N}$

The effect of addition of perchloric acid increases the value of rate constant $\mathrm{k}_{1}$ and the plot $1 / \mathrm{k}_{1}$ against $1 /$ [perchloric acid] has been found to be a straight line cutting an intercept from the ordinate (Figure -1). The addition of sodium perchlorate and barium perchlorate to the reaction mixture, do not produce any appreciable change in the rate of reaction (Table-4 and 5).

Table-4 Effect of addition of sodium perchlorate on the rate of reaction

\begin{tabular}{|c|c|c|c|c|c|c|c|}
\hline $\begin{array}{l}{\left[\mathrm{NaClO}_{4}\right]} \\
\text { N N }\end{array}$ & 0.00 & 0.25 & 0.50 & 0.75 & 1.00 & 1.25 & 1.50 \\
\hline $\begin{array}{l}k_{1} \times 10^{4} \\
\text { sec- }^{-1}\end{array}$ & 0.685 & 0.691 & 0.713 & 0.758 & 0.796 & 0.785 & 0.815 \\
\hline
\end{tabular}

Temperature $=50^{\circ} \mathrm{C} ;[$ Crotonic acid $]=4.00 \times 10^{-2} \mathrm{M} ;$ [Ceric perchlorate $]=4.00 \times 10^{-3} \mathrm{~N} ;[$ Perchloric acid $]=1.00 \mathrm{~N}$

Table-5 Effect of addition of barium perchlorate on the rate of re-
action
\begin{tabular}{|lllllll|}
\hline $\begin{array}{l}\left.\mathrm{Ba}\left(\mathrm{ClO}_{4}\right)_{2}\right] \\
(\mathrm{MX} 10) \\
\mathrm{k}_{1} \times 10^{4} \mathrm{sec}^{-1}\end{array}$ & 0.00 & 1.00 & 2.00 & 3.00 & 5.00 \\
\hline
\end{tabular}

Temperature $=50^{\circ} \mathrm{C}$; [Crotonic acid $]=4.00 \times 10-2 \mathrm{M}$; [Ceric perchlorate $]=4.00 \times 10-3 \mathrm{~N} ;[$ Perchloric acid $]=1.00 \mathrm{~N}$

The value of first order rate constant at different temperatures and the activation parameters are produced in Table 6 and 7 respectively.

Table-6 Effect of variation of temperature on the reaction velocity

\begin{tabular}{|lllll|}
\hline Temperature ${ }^{\circ} \mathrm{C}$ & 45 & 50 & 55 & 60 \\
k1X104 sec-1 & 0.478 & 0.685 & 1.262 & 2.214 \\
\hline
\end{tabular}

$\left[\right.$ Crotonic acid] $=4.00 \times 10^{-2} \mathrm{M}$; [Ceric perchlorate $]=4.00 \times 10^{-3} \mathrm{~N}$; [Perchloric acid] $=1.00 \mathrm{~N}$ 
Table-7 Activation parameters at Temperature $50^{\circ} \mathrm{C}$

\begin{tabular}{|lll|}
$\begin{array}{l}\text { Energy of activation } \\
(\Delta \mathrm{E}) \mathrm{k} . \mathrm{cal} / \mathrm{mol}\end{array}$ & $\begin{array}{l}\text { Entropy of activation } \\
(\Delta \mathrm{SH}) \text { e.u. }\end{array}$ & $\begin{array}{l}\text { Free Energy of activa- } \\
\text { tion }(\Delta \mathrm{E}) \mathrm{k} . \mathrm{cal} . / \mathrm{mol}\end{array}$ \\
\hline 24.03 & 1.03 & 23.69 \\
\hline
\end{tabular}

In perchloric acid $\mathrm{Ce}$ (IV) does not appear to form stable complexes with perchlorate ion but exists as $\mathrm{Ce}^{4+}, \mathrm{Ce}(\mathrm{OH})^{3+}, \mathrm{Ce}-\mathrm{O}-$ $\mathrm{Ce}^{6+}$ and $\mathrm{Ce}(\mathrm{OH})_{2}{ }^{2+}[19-25]$. Wiberg and Ford [26] have studied the equilibrium among the $\mathrm{Ce}$ (IV) species in aqueous acetic acid and have reported that principal equilibrium is between monomeric and trimeric species with the dimmer being relatively unimportant. The various hydrolytic equilibrium of the $\mathrm{Ce}$ (IV) species, in perchloric acid is illustrated in equation (1) to (5).

$$
\begin{aligned}
& \mathrm{Ce}^{4}+\mathrm{H}_{2} \mathrm{O} \stackrel{\mathrm{K}_{1}}{\leftrightarrows} \mathrm{Ce}(\mathrm{OH})^{3+}+\mathrm{H}^{+} \\
& 2 \mathrm{Ce}(\mathrm{OH})^{3+} \quad \stackrel{\mathrm{K}_{2}}{\leftrightarrows} \quad \mathrm{Ce}-\mathrm{O}-\mathrm{Ce}^{6+}+\mathrm{H}_{2} \mathrm{O} \\
& \mathrm{Ce}(\mathrm{OH})^{3+}+\mathrm{H}_{2} \mathrm{O} \stackrel{\mathrm{K}_{3}}{\leftrightarrows} \mathrm{Ce}(\mathrm{OH}) 2^{2+}+\mathrm{H}^{+} \\
& 3 \mathrm{Ce}(\mathrm{OH})^{3+} \quad \stackrel{\mathrm{K}_{4}}{\leftrightarrows} \quad \mathrm{Ce}_{3} \mathrm{O}_{3}{ }^{6+}+3 \mathrm{H}^{+} \\
& 2 \mathrm{Ce}(\mathrm{OH})^{3+} \quad \stackrel{\mathrm{K}_{4}}{\leftrightarrows} \mathrm{Ce}-\mathrm{O}-\mathrm{Ce} \mathrm{OH}^{5+}+\mathrm{H}^{+}
\end{aligned}
$$

The value of various hydrolytic constants for the equilibria given above, have been reported. However, the dependence of the existence of various species has not been clearly mentioned in the literature but the kinetic and spectrophotometric studies carried out by us suggest that the degree of association of ceric perchlorate in the perchloric acid medium depends on the initial concentration of ceric perchlorate and ph of the solution. Spectrophotometric studies in the U.V. range indicates that the absorbance in the range of $211 \pm 5 \mathrm{~m} \mu$ falls 1.11 to 0.55 when the initial concentration of $\mathrm{Ce}$ (IV) is increased from $0.62 \times 10^{-3} \mathrm{~N}$ to $6.67 \times 10^{-}$ ${ }^{3} \mathrm{~N}$. This signifies that at higher concentration the number of absorbing molecules decreases resulting into the formation of polymeric species. The predominant $\mathrm{Ce}$ (IV) species at lower concentration is $\mathrm{Ce}(\mathrm{OH})^{3+}$. The kinetic observation in Table 2, also indicates that an increasing the concentration of $\mathrm{Ce}$ (IV) - perchlorate, the value of $k_{1}$ decreases, which also suggested the formation of dimeric species at higher concentration because the behaviour is analogous to that observed in the oxidation of aldehydes [27] and alcohols by chromic acid[28]. This fact has not been reported so far in the kinetic studies of the oxidation of organic compounds by $\mathrm{Ce}$ (IV)-perchlorate. The spectrophotometric studies do not give any indication for the intermediate complex formation between $\mathrm{Ce}$ (IV) and the crotonic acid. The studies were carried out on PERKIN ELMER Spectrophotometer model-202. Considering the cataIytic behavior of $\left[\mathrm{H}^{+}\right]$on the rate of reaction, the reactive species would be the unhydrolysed $\mathrm{Ce}(\mathrm{IV})$ species [Ce $\left(\mathrm{H}^{2} \mathrm{O}\right){ }^{4+}$. The mechanism of the oxidation is visualized as below.

$$
\begin{aligned}
& \text { K1 } \\
& {\left[\mathrm{Ce}\left(\mathrm{H}_{2} \mathrm{O}\right)_{n-1} \mathrm{OH}\right]^{3+}+\underset{\mathrm{K}_{2}}{\stackrel{\mathrm{H}^{+}}{\leftrightarrows}}\left[\mathrm{Ce}\left(\mathrm{H}_{2} \mathrm{O}\right)_{n}\right]^{4+}} \\
& {\left[\mathrm{Ce}\left(\mathrm{H}_{2} \mathrm{O}\right)_{4}\right]^{4+}+\mathrm{CH}_{3} \mathrm{CH}=\mathrm{CHCOOH} \rightarrow\left[\mathrm{Ce}\left(\mathrm{H}_{2} \mathrm{O}\right)_{6}\right]^{3+}+\mathrm{H}^{+}+\text {Free radical }(7 \mathrm{a})} \\
& \text { Fast } \\
& \text { Free radical }+\left[\mathrm{Ce}\left(\mathrm{H}_{2} \mathrm{O}\right)_{\mathrm{n}}\right]^{4+} \rightarrow \operatorname{Product}+\left[\mathrm{Ce}\left(\mathrm{H}_{2} \mathrm{O}\right)_{6}\right]^{3+}+\mathrm{H}^{+}
\end{aligned}
$$

In this case also, we postulate the $\mathrm{C}-\mathrm{H}$ bond fission for the electron transfer the eq. (7a) which we assume to be the rate determining step. The oxidation of free radical by $\left[\mathrm{Ce}\left(\mathrm{H}_{2} \mathrm{O}\right)_{n}\right]^{4+}$, which is a fast process produces the product on further fragmentation through $\mathrm{C}-\mathrm{C}$ bond fission ${ }^{4}$. On the basis of the rate dependence of the reaction with respect to $\mathrm{Ce}$ (IV), we can write;

$-d / d t[C e(I V)]=k_{1}\left[\mathrm{Ce}(\text { IV) }]_{T}\right.$

Where [Ce (IV)] $\mathrm{T}$ indicates the total concentration of $\mathrm{Ce}$ (IV) in the reaction and $\mathrm{k} 1$ is the observed velocity constant. The value of $[\mathrm{Ce}(\mathrm{IV})]_{\mathrm{T}}=\left[\mathrm{Ce}\left(\mathrm{H}_{2} \mathrm{O}\right)_{n}\right]^{4+}+\left[\mathrm{Ce}\left(\mathrm{H}_{2} \mathrm{O}\right)_{\mathrm{n}-1} \mathrm{OH}\right]^{3+}$

Thus,

$$
\begin{aligned}
& \mathrm{k}_{2} \mathrm{~K}_{1}\left[\mathrm{H}^{+}\right][\text {Crotonic acid }] \\
& \mathrm{k}_{1}=\frac{(9)}{1+\mathrm{K}_{1}\left[\mathrm{H}^{+}\right]}
\end{aligned}
$$

The expression based on the postulated mechanism explains the observed facts that the order is unity with respect to crotonic acid and cerium (IV) and the plot of $1 / \mathrm{k} 1$ against $1 /\left[\mathrm{HClO}_{4}\right]$, will be straight line cutting an intercept from the ordinate as shown below;

$$
\begin{aligned}
& 1 / 1 \\
& 1 / k 1=1 \\
& k 2 K 1 \text { [H+] [Crotonic acid] k2 [Crotonic acid] }
\end{aligned}
$$

This also explains the insignificant effect of the addition of salt to the reaction mixture. The nature of the verification of the $k_{1}$ with the initial concentration of $\mathrm{Ce}$ (IV) can also be explained because at higher concentration the dimerisation of hydrolysed spices takes place and the rate expression will be modified following the appearance of dimeric spices at the cost of hydrolysed species. On higher concentration,

$[\mathrm{Ce}(\mathrm{IV})]_{\mathrm{T}}=\left[\mathrm{Ce}\left(\mathrm{H}_{2} \mathrm{O}\right)_{n}\right]^{4+}+\left[\mathrm{Ce}\left(\mathrm{H}_{2} \mathrm{O}\right)_{n-1}(\mathrm{OH})\right]^{3+}+\mathrm{Ce}-\mathrm{O}-\mathrm{Ce}^{6+}(11)$ And thus, we see that the value of $k 1$ will be reduced at higher concentration. In the oxidation of crotonic acid, the value of equivalents is found to be 11.232 after a sufficiently long time and thus the reaction can be shown to proceed in two different ways (12a) and (12b) giving rise to the products acetic and formic acid. The reaction precedes $30 \%$ through equation $12 a$ and $70 \%$ through equation $12 b$.<smiles>C/C=C\C(=O)O[18O]C(=O)[OH2+]</smiles>

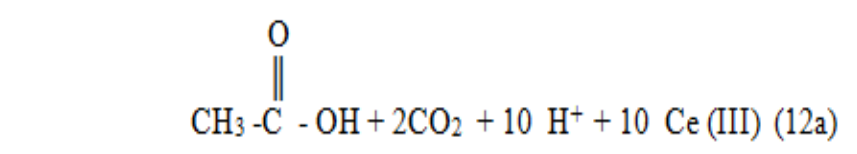

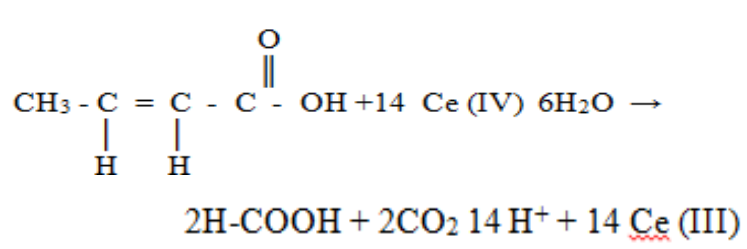




\section{Acknowledgement}

One of the authors (Rajesh Shukla) thankfully acknowledges the financial support provided by the University Grants Commission, New Delhi.

\section{References}

[1] Ardon M. (1957), J. Chem. Soc., 1811.

[2] Littler J.S. and Waters W.A. (1960) J. Chem. Soc., 2767, ibid, 832.

[3] Guelbault G.G. and McCurdy W.H. (1963) J. Phys. Chem., 67, 283.

[4] Paquetti D.and Zador M. (1968) Can. J. Chem., 46, 3507.

[5] Balasubramanian T.R. and Venkatasubramanian N. (1971) Ind. J. Chem., 9, 36; ibid, 9, 1243.

[6] Krishna B. and Tewari K.C. (1961) J. Chem. Soc., 3097.

[7] Mehrotra R.N. (1972) Ind. J. Chem., 10, 1077.

[8] Scagliarini G. (1926) Atti. Accad. Lincei,(6) 4, 204.

[9] Murchi L.E., Fernelius W.C., Mc Reynolds J.P. (1943) J. Am. Chem. Soc., 65, 329.

[10]Wolf L. and Barnighausen H. (1960) Acta Cryst., 13, 778., Inorg. Chem., 2, 235.

[11]Baker H.R., O' Rear J.G., Sniegaski P.J. and Kagarise R.E. (1961) U.S. Naval Res. Lab. Rept., 5641.

[12]Penny W.G., Anderson J.S. (1937) Trans. Faraday Soc., 33, 1363.

[13]Hanna S.B., Fenton J.T. (1983) Int. Jour. Chem. Kinetics, 15 (9), 925-940.

[14]Calvarusu G., Cavasino F.P. and Sbriziolo C. (1981) Int. Jour. Chem. Kinetics, 13(2), 135-148.

[15]Nagarajan S., Srinivasan K.S.V. (1998) Jour. Macromolecular Science, 38(1), 53-76.

[16]Dash S., Patel S. and Mishra B.K. (2009) Tetrahedron, 65, 707-739.

[17]Kumar D., Rani A., Prasad D.S.N. and Gupta K.S. (1991) Reaction Kinetics and Catalysis Letters, 43(1)133-141.

[18]Szaleo Z. (1952) Anal. Chem., 135, 269.

[19]Vogel A.I. (1969) A text book of quantitative inorganic analysis Longman Group Ltd., 316.

[20]Sherilly M.S., King C.B. and Spooner R.C. (1943) J. Am. Chem. Soc., 65,170.

[21]Duke F.R. and Parachen R.F. (1956) J. Am. Chem. Soc., 78,150 .

[22]Evans M.C. and Uri N. (1950) Nature, 166,602.

[23]Baker F.B., Newton T.W. and Khan M. (1960) J. Phys. Chem., 64, 109.

[24]Heidt L. and Smith M., (1958) J. Am. Chem. Soc., 70, 2476.

[25]Hardwick T.J., Robertson E. (1951) Can. J. Chem., 29, 818.

[26]King E.L., Pandow M.L. (1952) J. Am. Chem. Soc., 74, 1966.

[27]Wiberg K.B., Ford P.C. (1968) Inorg. Chem., 7, 169.

[28]Novik A., Westheimer F.H. (1943) J. Chem. Phys., 11,506.

[29]Wiberg K.B., Mill T. (1958) J. Am. Chem. Soc., 80, 3022. 